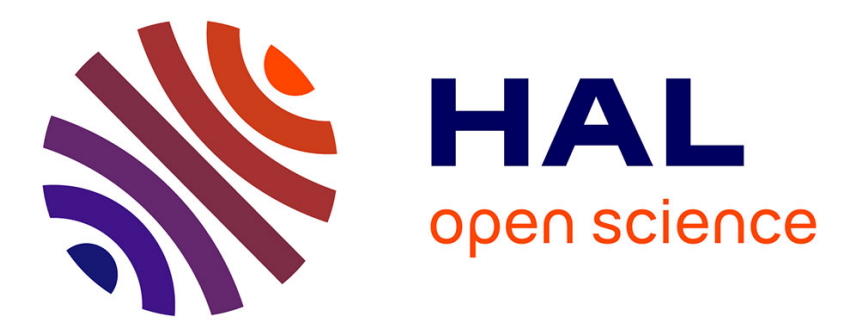

\title{
Novel Experimental Identification Method for a Supercapacitor Multipore Model in Order to Monitor the State of Health
}

Ronan German, Abderrahmane Hammar, Richard Lallemand, Ali Sari, Pascal

Venet

\section{To cite this version:}

Ronan German, Abderrahmane Hammar, Richard Lallemand, Ali Sari, Pascal Venet. Novel Experimental Identification Method for a Supercapacitor Multipore Model in Order to Monitor the State of Health. IEEE Transactions on Power Electronics, 2016, 31 (1), pp.548-559. 10.1109/TPEL.2015.2408457 . hal-01951301

\section{HAL Id: hal-01951301 https://hal.science/hal-01951301}

Submitted on 3 Jan 2019

HAL is a multi-disciplinary open access archive for the deposit and dissemination of scientific research documents, whether they are published or not. The documents may come from teaching and research institutions in France or abroad, or from public or private research centers.
L'archive ouverte pluridisciplinaire HAL, est destinée au dépôt et à la diffusion de documents scientifiques de niveau recherche, publiés ou non, émanant des établissements d'enseignement et de recherche français ou étrangers, des laboratoires publics ou privés. 


\title{
Novel experimental identification method for
}

\section{Supercapacitor Multi-Pore Model in order to}

\section{monitor the State of Health}

\author{
Ronan German ${ }^{\mathrm{a}}$, Abderrahmane Hammar ${ }^{\mathrm{a}, \mathrm{b}}$, Richard Lallemand ${ }^{\mathrm{b}}$, Ali Sari ${ }^{\mathrm{a}}$, Pascal Venet ${ }^{\mathrm{a}}$
}

\begin{abstract}
Supercapacitors (SCs) impedance modeling represents one important key to get information for SCs health monitoring and simulation. As a matter of fact, SCs behavior is dependent on various parameters such as pore size distribution of electrodes, electrolyte state, temperature, aging... We propose in this work to model supercapacitor taking into account physical considerations. Basing on theory on homogenous structure impedance, we define in first time, single pore (SP) model using uniform size of pores distribution. In the second step, we attempt to generalize this circuit model considering an electrode with different pores sizes or different penetrabilities of the pores. This model called multi-pore (MP) model (or multi-penetrability model) has been developed by our laboratories. This model allows to analyze the behavior of supercapacitor by modelling each group of electrode pores as a branch of an electrical equivalent circuit. This paper is the first in literature to give a simple and reproducible method for MP model parameters identification. The validity of the identification method will also be verified at different supercapacitor aging rates thanks to experimental aging tests.
\end{abstract}

Index Terms-Supercapacitors, Electrochemical Double Layer Capacitors, Ultracapacitors, Single Pore model, Multi-Pore model, Electrical Equivalent Circuit, Impedance modeling, Experimental Identification, Aging

Affiliation a concerns the Université Lyon 1, Université de Lyon, Laboratoire Ampère, UMR CNRS 5005, Villeurbanne Cedex, F-69622, France. E-mail : firstname.name@univ-lyon1.fr

Affiliation b concerns IFSTTAR, France, E-mail : firstname.name@ifsttar.fr 


\section{INTRODUCTION}

$\mathrm{S}$ upercapacitors (SCs) [1] [2], also called Electrochemical Double Layer Capacitors [3] or Ultracapacitors [4][5], are electrical

energy devices with high power density and high expected reliability [6]. In addition, they express more temperature stability than other energy storage devices as they don't imply chemical reactions for energy storage. As a consequence, high number of cycles is possible with high charge/discharge currents[7]. Nowadays, they become an attractive alternative storage device for several applications (such as energy storage device for opening the emergency doors of Airbus A 380, energy source in electric vehicles [8], in uninterruptible power supplies [9] or in power grids ). They may be used as the only energy and power device or in combination with other energy supplies like batteries [10] or fuel cells in hybrid energy storage systems [11]...

Some electrical applications like railway [12] [13] and electrical traction systems present high dynamics constraints. In such applications it appears to be very important to model the energy storage systems for simulation or maintenance (health monitoring [6]) purposes.

Impedance measurement provides a powerful tool of analysis [14] and investigation [15]. Ideally, electrical parameters of any electrical model must reflect physical and electrochemical phenomena of SCs. It may allow observation and comprehension of the evolution of the state of health of supercapacitor with aging [6].

In this paper, we use impedance spectroscopy technique to characterize supercapacitors. In a first time, we present single pore (SP) model [16]. In this case we consider that pore size on SC electrodes is constant. In the second step, we present the multipore model which takes into account the pore size dispersion of SCs electrodes.

Then we propose a new identification method for extracting the equivalent parameters of the MP model. This method differs from the classical optimization methods used for identification methods (based on fitting between experimental data and model) which leads to issues such irreproducible results (several sets of equivalent parameters can lead to the same fitting quality). The presented method is based on the physics of ions penetration in SC electrodes. The method separates the SC impedance spectrum in different influence zones as a function of ionic storage speed in each pore groups. The equivalent parameters of the fastest pore group are firstly identified with high frequencies. Then, slower pore groups are identified in lower frequencies. It results in fast computing and reproducible results.

Commercial 3000F SCs from two different manufacturers (A and B) built with the most widespread technology (carbon/carbon electrodes and organic acetonitrile/TEABF 4 electrolyte [17]) are characterized using impedance spectroscopy method at different aging rates during aging tests. Thus, we can observe aging results with MP model. Another possible use of MP model is also presented (time simulation) to illustrate its versatility. 


\section{SCS IMPEDANCE MODELING}

\section{A. Energy storage mechanisms for SCs}

Fig. 1 presents operating principles of SC. SC are composed of porous electrodes facing each other and drawn in an ionic electrolyte. The separator is a porous structure preventing electrical short-circuit between electrodes while permitting the movement of ions. Collectors are connecting electrodes and external circuit. Energy is stored by the double layer effect (one ionic charge facing one electronic opposite charge) contrary to film capacitors which only use electric charges [18]. All the SCs we are testing are manufactured with the same electrolyte/electrode technology. This technology is the most widespread for high capacitance SCs. The electrolyte solvent is Acetonitrile (ACN) and the ionic salt is tetraethylammonium tetrafluoroborate $\mathrm{ET}_{4} \mathrm{NBF}_{4}\left(\right.$ also called $\mathrm{TEABF}_{4}$ ). Nowadays ACN appears to be the best compromise between high conductivity, high relative dielectric constant $\left(\varepsilon_{\mathrm{R}}=37\right)$ [19] and low temperature of freezing (around $-40{ }^{\circ} \mathrm{C}$ ) although it is classified as hazardous and flammable. $\mathrm{ET}_{4} \mathrm{NBF}_{4}$ crystallization temperature is also very low and permits $\mathrm{SC}$ to function normally for temperatures between $-30^{\circ} \mathrm{C}$ and $65{ }^{\circ} \mathrm{C}$ [17]. The electrodes are built with a porous material to maximize the contact surface between electrode and electrolyte. Activated carbon (AC) is relatively abundant and cheap as it can be manufactured from nutshells [20].The surface (S) of electrodes built with AC is usually around $2000 \mathrm{~m}^{2} / \mathrm{g}$ [21]. As there is no dielectric film the distance between ions and opposite sign charges $(d)$ is very thin which influences greatly the double layer capacitance $\left(C_{d l}\right)$ of electrode as shown on (1).

$$
C_{d l} \approx \frac{\varepsilon_{R} \cdot \varepsilon_{0} \cdot S}{d}
$$

where $\varepsilon_{0}$ is the dielectric permittivity of the vacuum. Combining the thin double layer and the high energy storage surface developed by AC, SCs are able to develop capacitance up to $3000 \mathrm{~F}$ for a mass of $0.6 \mathrm{~kg}$ [17]. As there are no reactions implied in energy storage (contrary to batteries) the equivalent series resistance (ESR) is very low and the lifespan of component is very high compared to batteries. Nevertheless the amount of mass energy stored $(\approx 5 \mathrm{Wh} / \mathrm{kg}[17])$ is inferior compared to batteries such as Li-ion batteries [22]. To sum up, SCs are robust energy storage systems (ESSs) (temperatures range, long lifespan) capable to reach high capacities values and to achieve high power profiles during short time (for example braking energy recovery). 


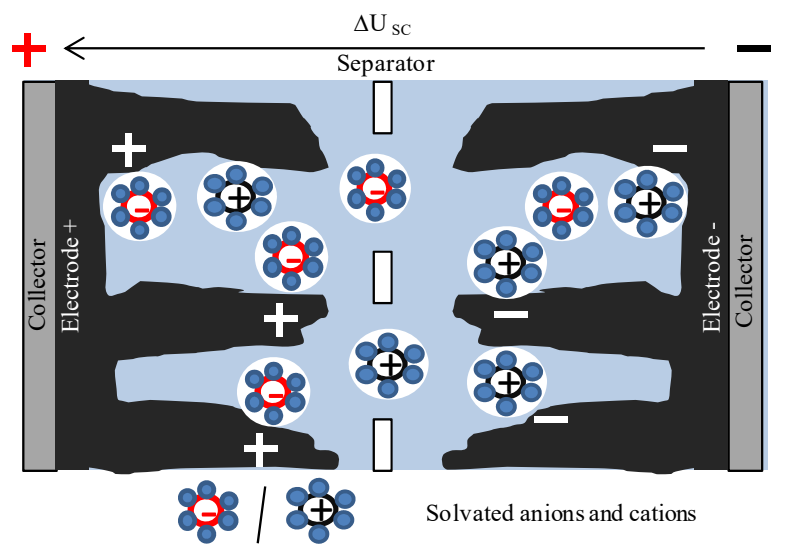

Fig. 1 Supercapactior working principle

Fig. 2 presents the evolution of a SC capacitance with frequency. Capacitance is calculated with the imaginary part of SC impedance $\left(Z_{\mathrm{SC}}\right)$.

$$
C_{d l}=-\frac{1}{\omega \cdot \operatorname{Im}\left(Z_{S C}\right)}
$$

We can notice on Fig. 2 that capacitance of the tested SC is constant in low frequency (LF) and brutally drops down when frequency increases. SCs are indeed low frequency (LF) energy storage systems because of the use of ions in the energy storage process (the movement of ions is far much slow than the movement of the electric charges in conductive materials). Thus, we define for the rest of the article the HF zone for frequencies superior to $300 \mathrm{mHz}$ and the LF zone for frequencies inferior to $300 \mathrm{mHz}$.

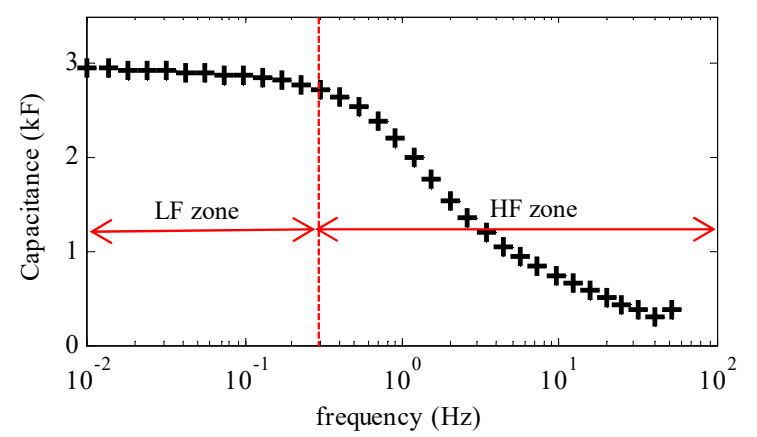

Fig. 2 The two different frequency zones for energy storage in tested SCs

Fig. 3 shows the impedance spectrum of a tested SC obtained by impedance spectrometer under excitation amplitude of 5 A. Frequency sweep covers the range from $10 \mathrm{mHz}$ to $40 \mathrm{~Hz}$. The frequency behavior of a SC can be decomposed into two asymptotic zones. High frequency (HF) zone $\left(\alpha_{\mathrm{HF}}=45^{\circ}\right.$ in an orthonormal plot) is characteristic of the increasing penetration depth of ions into the porous structure with lower frequency [16] (see Fig. 4). The series resistance $\left(\mathrm{R}_{0}\right)$ can be calculated as being the real part of impedance when the high frequency asymptote cuts the real axis. It represents the resistive phenomenon which are 
not linked to porosity (connection related resistance for instance). The low frequency (LF) zone corresponds to the capacitive energy storage zone in SC electrode porous structure (negative imaginary part). SC electrode is composed of pores which don't have exactly the same geometry (depth and diameter). This property is called pore size dispersion and it affects the low frequency SC behavior (penetration depth of ion is also depending on the ion size and pore size ratio as shown on Fig. 4) [23]. The non infinite LF slope $\left(\alpha_{\mathrm{LF}} \neq 90^{\circ}\right)$ is a consequence of the sluggish redistribution of charges between pores of different characteristics (geometry, accessibility...) [23]. The accessibility resistance of electrolyte in the pore $\left(\mathrm{R}_{\mathrm{el}}\right)$ can be calculated with the value of $\mathrm{R}_{0}$ and the HF and LF asymptotes as shown on Fig. 43. It is mostly influenced by the difficulty of ions to go throughout the pores.

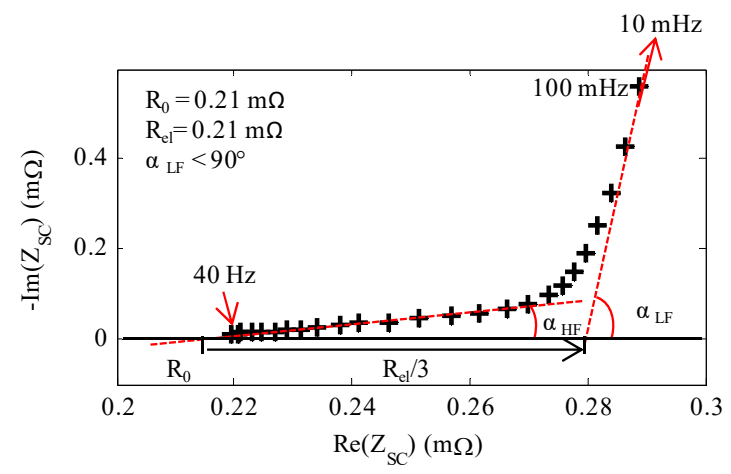

Fig. 3. SC impedance spectrum Nyquist diagram for $100 \mathrm{mHz}$ to $40 \mathrm{~Hz}$

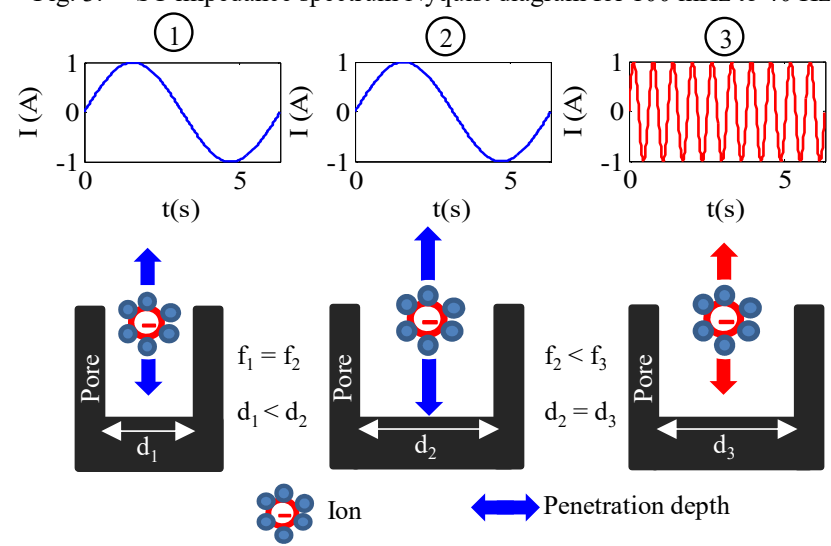

Fig. 4. Evolution of ion penetration depth with electrical signal frequency

\section{B. Single pore (SP) model}

Single pore (SP) has been discovered by de Levie in 1967 [16]. It describes the impedance of a perfect porous structure (see Fig. 5b) in which :

- $\quad$ Pore length $>>$ Pore diameter

- Pores are parallel and have exactely the same dimensions

- There is no concentration gradient in the electrolyte 
The impedance expression of a SP pourous structure is depending of two parameters called the accessibility resistance of electrolyte in the pores $\left(\mathrm{R}_{\mathrm{el}}\right)$ and the double layer capacitance of the SP porous structure $\left(\mathrm{C}_{\mathrm{dl}}\right)$. They are representing respectively the difficulty of ions to reach the bottom of pores and the capability of the SP structure to store energy. The expression of the impedance of a SP structure $\left(Z_{\mathrm{SP}}\right)$ is given by the following expression [16]. This equation is the classic expression for porous structure impedance.

$$
Z_{\mathrm{SP}}=\sqrt{\frac{\mathrm{R}_{\mathrm{el}}}{\mathrm{j} \omega \cdot \mathrm{C}_{\mathrm{dl}}}} \cdot \operatorname{coth} \sqrt{\mathrm{j} \omega \cdot \mathrm{C}_{\mathrm{dl}} \mathrm{R}_{\mathrm{el}}}
$$

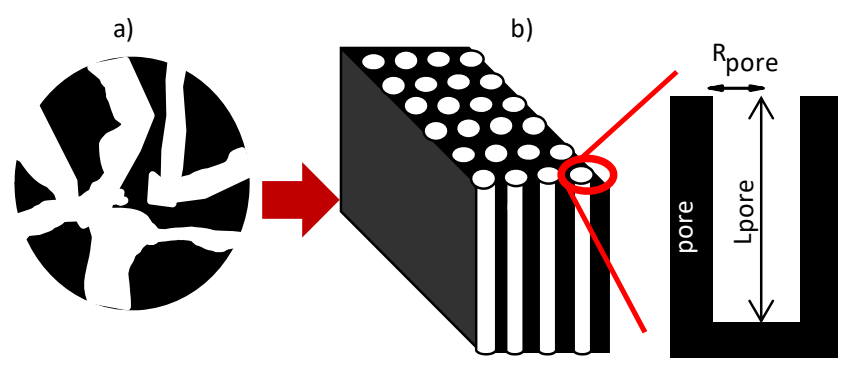

Fig. 5 Simplification of the activated carbon grain a) with SP model hypothesis b)

Equation (3) can be simplified in HF and in LF. As a matter of fact :

$$
\begin{gathered}
\lim _{x \rightarrow \infty} \operatorname{coth}(x)=1 \\
\lim _{x \rightarrow 0} \operatorname{coth}(x)=\frac{1}{x}+\frac{x}{3}
\end{gathered}
$$

Thus, for HF the SP model impedance expression becomes :

$$
\begin{aligned}
\lim _{\omega \rightarrow \infty} & \sqrt{\frac{\mathrm{R}_{e l}}{j \omega C_{d l}}} \times \operatorname{coth}\left(\sqrt{j \omega C_{d l} R_{e l}}\right)=\frac{1}{\sqrt{j}} \sqrt{\frac{\mathrm{R}_{e l}}{\omega C_{d l}}} \\
= & \left(\frac{\sqrt{2}}{2}-j \cdot \frac{\sqrt{2}}{2}\right) \sqrt{\frac{\mathrm{R}_{e l}}{\omega C_{d l}}}
\end{aligned}
$$

Thus

$$
\frac{d\left(-\operatorname{Im}\left(Z_{S P}\right)\right)}{d\left(\operatorname{Re}\left(Z_{S P}\right)\right)}=1
$$

Thus the slope of HF asymptote behavior (see Fig. 6) of the SP model will be a $45^{\circ}$ straight line (only for an orthonormal nyquist plot). For LF the SP model acts like a perfect capacitance in series with a $\mathrm{R}_{\mathrm{el}}$ series resistance. This frequency is characteristic of an occupation of the whole porosity by the ions (ions have enough time to reach the pore bottom). 


$$
\lim _{\omega \rightarrow 0} \sqrt{\frac{\mathrm{R}_{e l}}{j \omega C_{d l}}} \cdot \operatorname{coth}\left(\sqrt{j \omega C_{d l} R_{e l}}\right)=\left(\frac{1}{j \omega C_{d l}}+\frac{R_{e l}}{3}\right)
$$

If we call $\mathrm{R}_{\text {elpore }}$ and $\mathrm{C}_{\mathrm{dlpore}}$ the accessibility resistance of electrolyte in one pore and the double layer capcitance of one pore then the global parameters of the $\mathrm{n}$ parallel pores of the SP structure will be given by the following expressions.

$$
\begin{gathered}
\mathrm{R}_{e l}=\frac{\mathrm{R}_{\text {el Pore }}}{n} \\
C_{d l}=n \times C_{d l \text { Pore }} \\
\tau=R_{e l} \times C_{d l}=R_{e l \text { Pore }} \times C_{d l \text { Pore }}
\end{gathered}
$$

$\tau$ is the time constant of the SP structue. As shown in (9) it only depends on the parameters of one pore $\left(\mathrm{R}_{\text {elpore }}\right.$ and $\left.\mathrm{C}_{\mathrm{dlpore}}\right)$. The cutoff frequency $\left(\mathrm{f}_{\mathrm{C}}\right)$ is defined considering the $\tau$ value of the pores of the SP structure.

$$
f_{c}=\frac{1}{2 \pi \cdot R_{e l} \cdot C_{d l}}=\frac{1}{2 \pi \cdot \tau}
$$

By placing the cutoff frequency in Fig. 6, we can notice that this variable is representative of the highest frequency for which the SP structure acts like a perfect capacitor with a series resistance (LF asymptote). For frequencies superior to $f_{C}$ the ions are not occupying the totality of pore depth and for frequencies inferior to $f_{C}$ the whole SP porosity is filled with ions. The more $f_{C}$ is high (the more $\tau$ is small), the more the SP structure is quick for ion storage (the more the pores are accessible for ions). The inverse transformation of $Z_{\mathrm{SP}}(j \omega)$ in the time domain is given by:

$$
Z_{S P}(t)=\frac{1}{C_{d l}}+\frac{2}{C_{d l}} \cdot \sum_{n=1}^{\infty} e^{-\frac{2}{R_{n} \cdot C_{d l}} t}
$$

with:

$$
R_{n}=\frac{2 \cdot R_{e l}}{n^{2} \pi^{2}}
$$

The equivalent circuit of the SP structure is presented in Fig. 7. A $\mathrm{R}_{0}$ resistance has been added in series to model the effect of resistance cause by contacts and resistivity of components used for SCs manufacturing. 


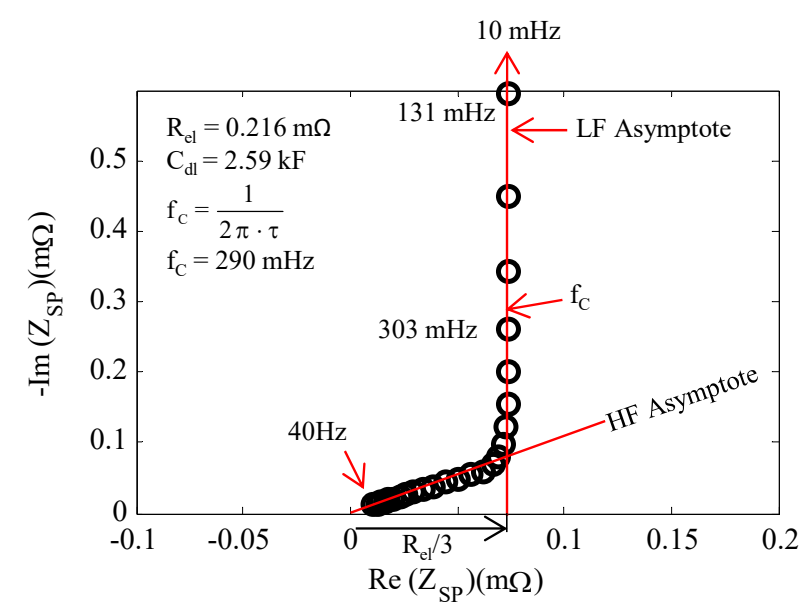

Fig. 6 Nyquist plot of SP model frequency behavior

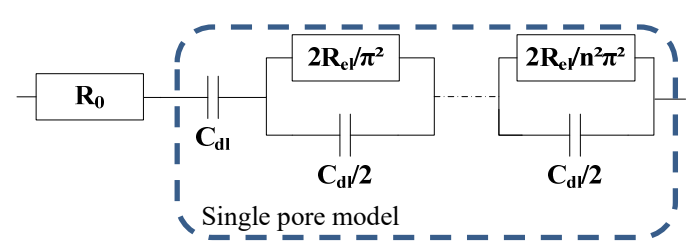

Fig. 7 SP model equivalent circuit

Fig. 8 presents the comparison between the experimental impedance spectrum of a SC and the SP model. 


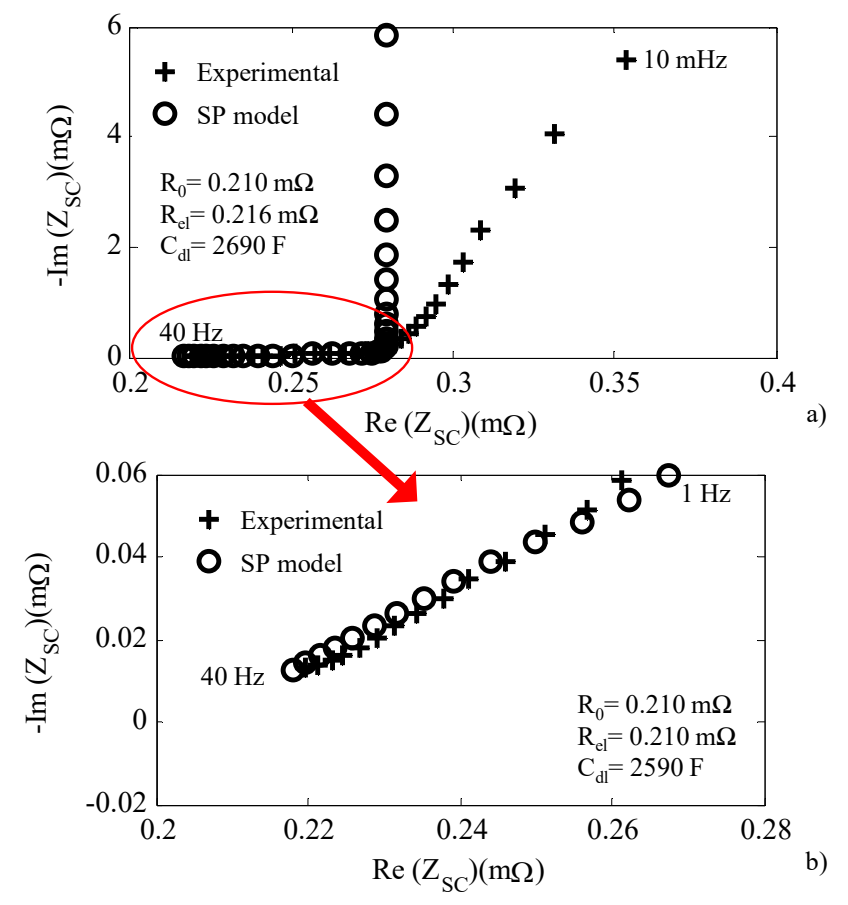

Fig. 8 Comparison of experimental SC spectrum from manufacturer B and single pore model (whole frequency bandwidth) a) and detail of the higher part of frequency bandwidth b)

Part a) of Fig. 8 shows that the LF behavior of SC impedance diverges from the SP model. This part shows that the hypothesis formulated by De Levie (especially the pore size unicity) are not applicable to SC impedance. The non infinite slope of impedance in LF is indeed associated with distributed porous structures [23]. Nevertheless the Part b) of Fig. 8 shows that the SP model is able to represent accurately the HF behavior of the SC impedance. Those evidences tend to show that at high frequency only a group of pores stores energy and that for LF several pore groups are able to store energy. Thus we can conclude that the major drawback of the SP model is being unable to take into account pore size dispersion to model accurately SCs energy storage for LF.

\section{Constant phase element (CPE) model}

Industrial processes to activate carbon lead to dispersion for pore size. 
Table 1 presents an example of pore distribution on three different types of PICA activated carbon porous electrodes. The pores are divided in three categories by the manufacturer. Large pores have an entrance diameter superior to $500 \AA$. Medium pores diameter between $20 \AA$ and $500 \AA$. Small pore diameter is inferior to $20 \AA$. The specific surface of electrodes corresponds to the maximum contact surface between electrode and electrolyte and is given in $\mathrm{m}^{2}$ for 1 gram of electrode. The proportion of each category of pores is given in $\mathrm{cm}^{3}$ for 1 gram of electrode. 
Table 1 pore size distribution for three PICA activated carbon used as electrodes [21]

\begin{tabular}{cccccc}
\hline Type & $\begin{array}{c}\text { Specific } \\
\text { surface } \\
\left(\mathrm{m}^{2} / \mathrm{g}\right)\end{array}$ & $\begin{array}{c}\text { Median } \\
\text { pore } \\
\text { diameter } \\
(\AA)\end{array}$ & $\begin{array}{c}\text { Large } \\
\text { pore } \\
\text { volume } \\
\left(\mathrm{cm}^{3} / \mathrm{g}\right)\end{array}$ & $\begin{array}{c}\text { Medium } \\
\text { pore } \\
\text { volume } \\
\left(\mathrm{cm}^{3} / \mathrm{g}\right)\end{array}$ & $\begin{array}{c}\text { Small } \\
\text { pore } \\
\text { volume } \\
\left(\mathrm{cm}^{3} / \mathrm{g}\right)\end{array}$ \\
\hline 1 & 1937 & 24.2 & 0.70 & 0.87 & 1.57 \\
2 & 1960 & 19.6 & 0.65 & 0.44 & 1.09 \\
3 & 1170 & 10.8 & 0.43 & 0.16 & 0.59 \\
\hline
\end{tabular}

Electrodes built with activated carbon have a wide pore distribution. This is why SP model is unable to represent properly low frequency SC impedance behavior. Then pore size distribution has to be taken into account in our model as depicted in Fig. 9.

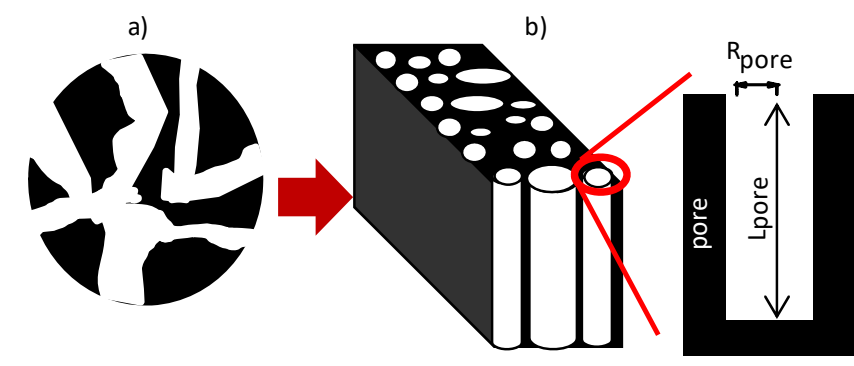

Fig. 9 Simplification of the activated carbon grain a) with CPE model hypothesis b)

Impedance of distributed porous structure is often described by a CPE [23]. To take into account of the impact of pore size dispersion on low frequency SC impedance, Kötz and al. in [24] proposed to replace the capacitive element $\mathrm{C}_{\mathrm{dl}}$ by a CPE element $\left(\mathrm{C}_{\mathrm{dl}}, 1-\gamma\right)$ in single pore model equation (3). Equation (13) gives the expression of the CPE model impedance.

$$
Z_{\text {CPEModel }}=R_{0}+\sqrt{\frac{R_{e l}}{(j \omega)^{1-\gamma} C_{d l}}} \times \operatorname{coth}\left(\sqrt{(j \omega)^{1-\gamma} C_{d l} R_{e l}}\right)
$$

where $\gamma$ is the pore size dispersion $(\gamma=0$ for a single pore size electrode, the more dispersed the electrode pores are the nearer to $1 \gamma$ is. $\mathrm{R}_{\mathrm{el}} \mathrm{C}_{\mathrm{dl}}$, representing the accessibility of electrolyte in the pores and the global capacitance of SC for LF. The equivalent circuit of CPE model is also derived from the SP one by replacing the capacitors by CPE as depicted in Fig. 10.

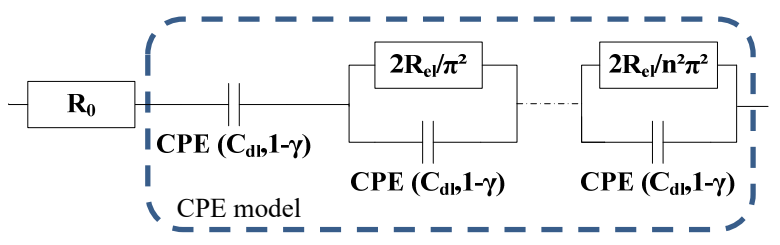

Fig. 10 CPE model equivalent circuit

Fig. 11 shows the plots of experimental SC and the CPE model. Presented results have been obtained for a $3000 \mathrm{~F}, 2.7 \mathrm{~V}$ component. This figure validates CPE model as it fits well with the experimental impedance spectrum in the whole frequency range 
of our experiments (HF and LF). Thus the adjunction of the dispersion factor $\gamma$ provides a huge improve in term of fitting precision compared to SP model. Nevertheless $\gamma$ is a global parameter which is not able to differentiate the pore as a function of their geometrical (thus electrical) parameters. To conclude, we can say that CPE model is a powerful tool for SCs behavior simulation but it can be improved for fine SCs analysis (such as SC aging monitoring).

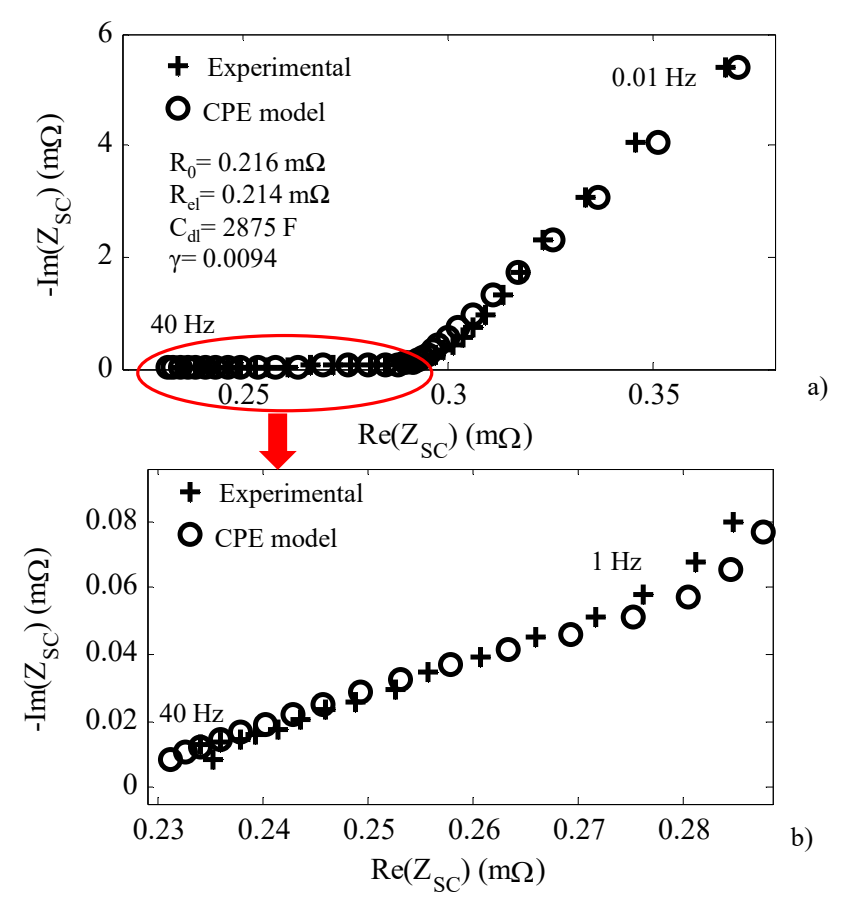

Fig. 11 Comparison of experimental SC spectrum from manufacturer B and CPE model (whole frequency bandwidth) a) and detail of the higher part of frequency bandwidth b)

\section{PRINCIPLE OF THE MUlTiPORE (MP) MODEL}

The CPE model was consequently developed to take into account the effect of pore size dispersion (the redistribution of charges between different size pores) by using the dispersion parameter $\gamma$. The issue of this model is that $\gamma$ parameter doesn't give particular information on the different pore groups present on the electrodes. A. Hammar [25] decided to go for a totally new model by splitting the electrode into k pore groups. Those k groups are called branches (see Fig. 13). We conserve the hypothesis of parallel and cylindrical pores formulated by De Levie for SP model. The $n_{i}$ pores of the the $i^{\text {th }}$ branch (with $n_{i} \cdot R_{\text {elii }}, C_{\text {dil }} / n_{i}$ impedance characteristics) are grouped in the $\mathrm{SP}_{\mathrm{i}}$ porous structure. The impedance $\mathrm{SP}_{\mathrm{i}}$ porous structure is called $\mathrm{Z}_{\mathrm{pi}}$. Parameters $Z_{\mathrm{pi}}, \mathrm{R}_{\mathrm{eli}}, \mathrm{C}_{\mathrm{dli}}$ depend on the impedance of one pore and the number $\mathrm{n}_{\mathrm{i}}$ of the parallel pores in the group. Each group of pores is represented as a parallel branch on the equivalent circuit as shown in Fig. 12. 


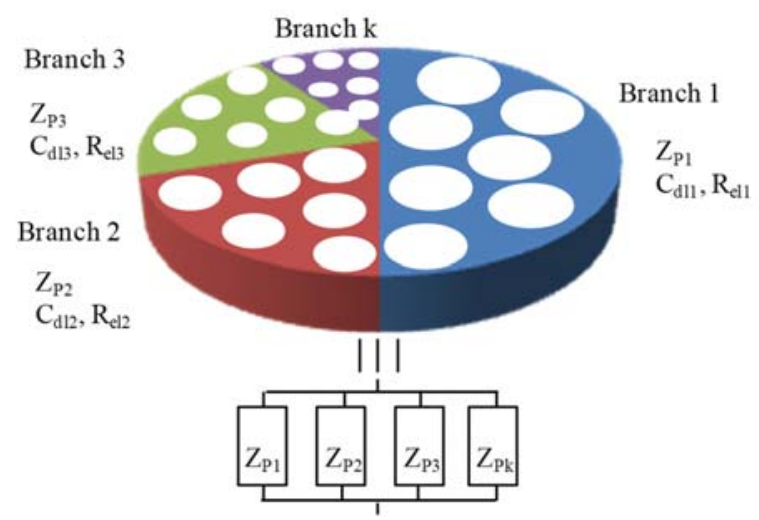

Fig. 12 Principle of MP model (grouping the same pores into branches)

Impedance of the global MP porous structure is thus composed with several SP branches as depicted in Fig. 13.This model can be considered as a generalization of SP model. The impedance of SC is obtained by adding a series resistance $\mathrm{R}_{0}$ which is modeling the resistivity of contacts and the limited conductivity of SCs constituents (electrodes, collectors...).

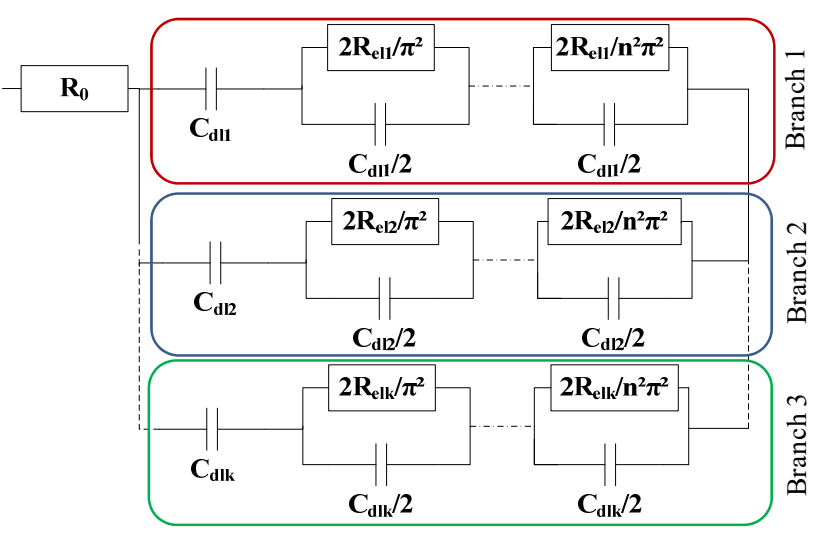

Fig. 13 MP model equivalent circuit

\section{IDENTIFICATION METHOD FOR MULTIPORE (MP) MODEL}

\section{A. Principle}

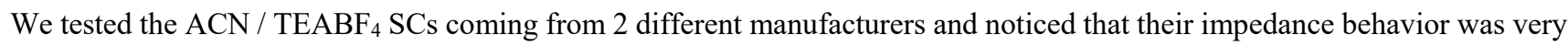
similar to a SP porous structure for HF zone as depicted in Fig. 14. This indicates that in HF only one group of pore (one branch in Fig. 13) participates to energy storage. This branch is the most accessible for the ions. That means that the pore geometrical configuration is adapted for a quick ionic storage. By convention, we sort the branches by accessibility order (the number 1 will be for the most accessible branch) thus by time constant opposite order.

$$
\tau_{1}<<\ldots<\tau_{n}
$$

If we consider that all the pores have the same length their accessibility can be associated only with pore diameter (the more the 
pore diameter is big and the more accessible the pore is) [6]. Fig. 15 presents the different frequency zones corresponding to the respective influence of each branch. In HF only branch 1 is participating to energy storage. That means that other branch are not storing energy because they are not accessible (i.e. quick) enough to let ions go through at such frequencies. Consequently, for HF, other branches are acting as open circuit in the MP model equivalent circuit (see Fig. 13). When frequency decreases the branch 2 starts to store energy too. Branch 1 and branch 2 are acting in parallel. Then for lower frequencies the number of active branches is increasing. The proposed model with parallel SP branches is limited to double layer SCs (corresponding to the most widespread SCs technology for high power applications and to the tested components in this paper) as SP structure is purely associated with double layer energy storage. SCs using pseudo capacitance as a major storage mechanism have a different impedance spectrum in high frequency due to charge transfer and are more close to battery [26]. Thus, even though the principle of branches identification by frequency zone can be applied to pseudo capacitive SCs, a specific model with supplementary equivalent parameters has to be developped.
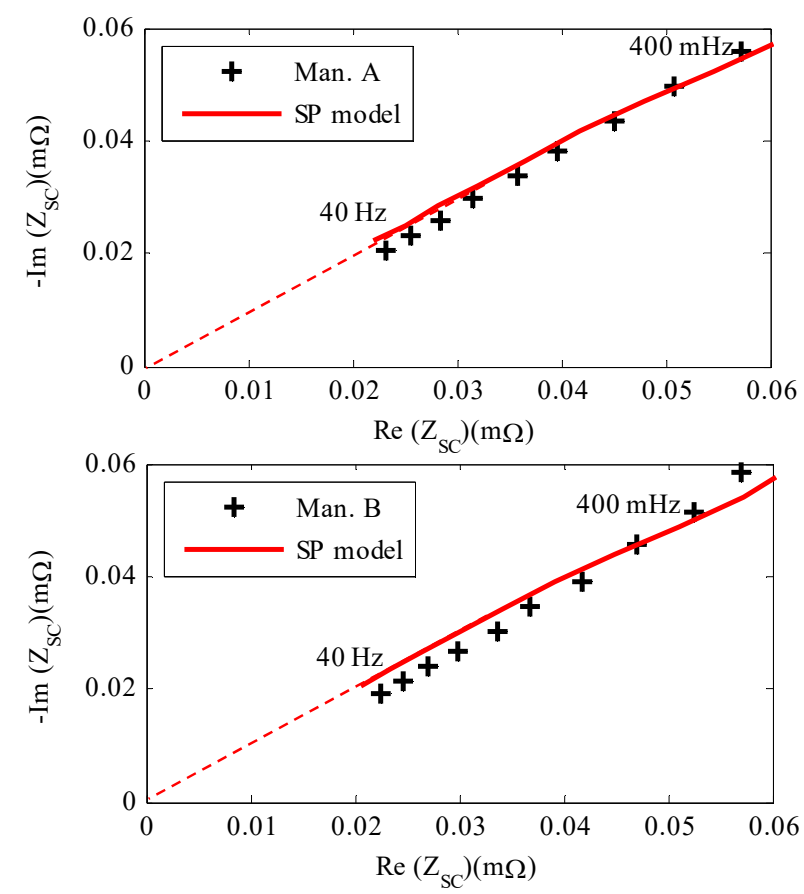

Fig. 14 Comparison of SP model and porous structures impedances for manufacturers A and B ( $\mathrm{R}_{0}$ removed from SCs impedance) 


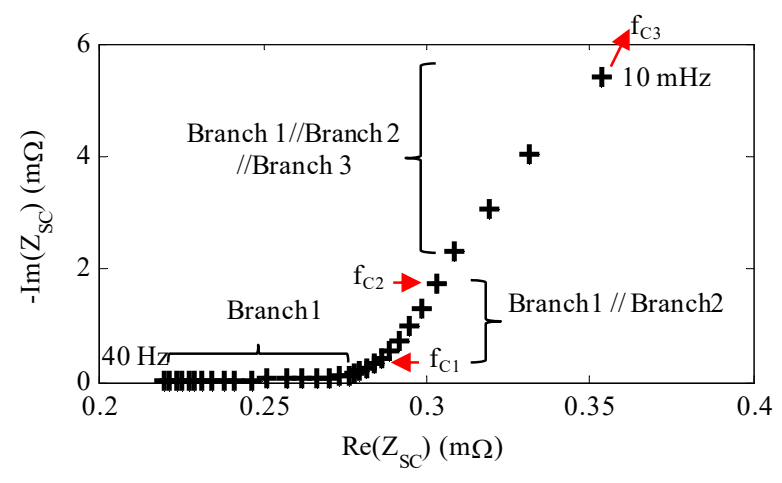

Fig. 15 Influence zone of different branches for MP model

The principle of our identification method consists in identifying the frequency influence zones of the branches (thanks to their cutoff frequency $\mathrm{f}_{\mathrm{Ci}}$ ) and their electrical parameters (one after another). The identification method will be accomplished from HF to LF. The first branch to identify is branch 1 as it is the only one to act form HF to $f_{\mathrm{C} 1}$ (see Fig. 15). Then branch 2 is identified from $\mathrm{f}_{\mathrm{C} 1}$ to $\mathrm{f}_{\mathrm{C} 2}$ thanks to the parameters of branch 1 and the experimental impedance spectrum. The higher rank branches $(3,4 \ldots . . \mathrm{n})$ are extracted the same way. The next parts give more details and examples for branches identification.

\section{B. Identification method for branch 1}

For HF SCs impedance behavior is very near to a SP structure. We need to identify the branch 1 of SC electrode as a SP model. This part provides the method for identification of a single pore structure. We consider a perfect SP structure (without $\mathrm{R}_{0}$ series resistance). We simplify in a first time the writing of the SP structure impedance expression (3) in equations (15) and (16) with frequency dependent resistance $\left(\mathrm{R}_{1}(\mathrm{f})\right)$ and capacitance $\left(\mathrm{C}_{1}(\mathrm{f})\right)$ as depicted on Fig. 16

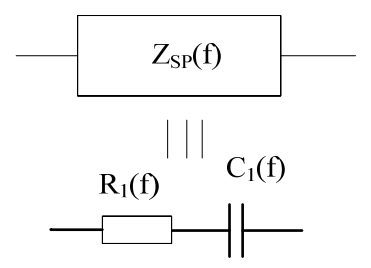

Fig. 16 Simplification of SP model

where:

$$
\begin{aligned}
& R_{1}(f)=\operatorname{Re}\left(Z_{S P}(f)\right) \\
& C_{1}(f)=\frac{-1}{\operatorname{Im}\left(Z_{S P}(f)\right) \cdot 2 \pi \cdot f}
\end{aligned}
$$

For the cutoff frequency $\left(\mathrm{f}_{\mathrm{C} 1}\right)$ the asymptotic LF behavior of SC impedance has been reached (see part II.B and Fig. 6). Then we can write equations (17) and (18): 


$$
\begin{aligned}
& R_{1}\left(f_{c 1}\right) \approx \frac{R_{e l 1}}{3} \\
& C_{1}\left(f_{c 1}\right) \approx C_{d l 1}
\end{aligned}
$$

Then we simplify the expression of $f_{\mathrm{C} 1}$ with (17) and (18).

$$
f_{c 1}=\frac{1}{2 \pi \cdot R_{e l 1} \cdot C_{d l 1}} \Leftrightarrow f_{c 1} \approx \frac{1}{2 \pi \cdot 3 \cdot R_{1}\left(f_{c 1}\right) \cdot C_{1}\left(f_{c 1}\right)}
$$

We extract the value of the cutoff frequency by using the frequencies of impedance measurement (f) and by solving (20).

$$
f \approx \frac{1}{2 \pi \cdot 3 \cdot R_{1}\left(f_{c 1}\right) \cdot C_{1}\left(f_{c 1}\right)} \Leftrightarrow f=f_{c 1}
$$

Equation (20) is solved graphically in Fig. 17.

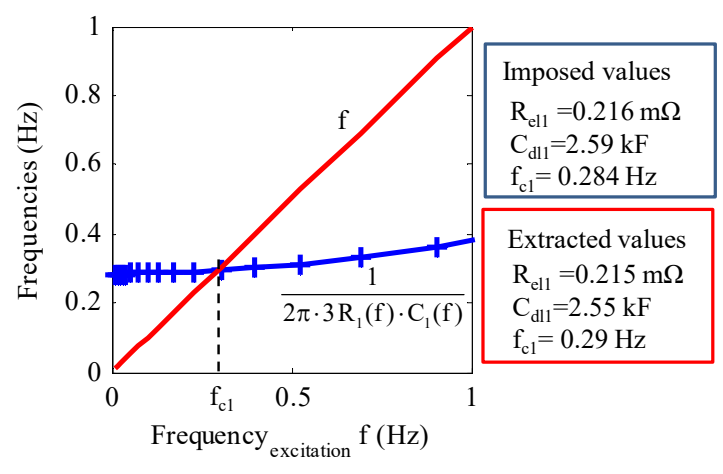

Fig. 17 Method to identify the cutoff frequency $f_{\mathrm{C} 1}$

To show the good precision of such an identification method we impose the values of SP porous structure (imposed values in Fig. 17) and simulate the impedance behavior with frequency (see equation (3)). Then we identified the cutoff frequency $\mathrm{f}_{\mathrm{C} 1}$ (as described in Fig. 17) and calculate the values $\mathrm{R}_{\mathrm{ell}}$ and $\mathrm{C}_{\mathrm{d} 11}$ with (17) and (18). The extracted parameters are very near from the imposed values with differences of the percent order or inferior. This values show that the described identification method is very precise. Then we apply the identification method on experimental SC impedance $\left(Z_{S C}\right.$ EXP). As we are treating with experimental impedance a $\mathrm{R}_{0}$ series resistance must be added to the branch $1\left(\mathrm{Z}_{\mathrm{Branch} 1}\right)$.

$$
Z_{\text {Branchl }}=R_{0}+\sqrt{\frac{R_{e l 1}}{j \omega \cdot C_{d l 1}}} \times \operatorname{coth}\left(\sqrt{j \omega \cdot C_{d l 1} \cdot R_{e l 1}}\right)
$$

Thus $\mathrm{R}_{1}(\mathrm{f})$ and $\mathrm{C}_{1}(\mathrm{f})$ expressions are slightly changed:

$$
\begin{gathered}
R_{1}(f)=\operatorname{Re}\left(Z_{\text {SC Exp }}(f)-R_{0}\right) \\
C_{1}(f)=\frac{-1}{\operatorname{Im}\left(Z_{\text {SC Exp }}(f)-R_{0}\right) \cdot 2 \pi \cdot f}
\end{gathered}
$$


The extraction of $f_{\mathrm{C} 1}$ with (20) gives a cutoff frequency of $290 \mathrm{mHz}$. We calculate $\mathrm{R}_{\mathrm{el} 1}$ and $\mathrm{C}_{\mathrm{d} 11}$ with the following expressions.

$$
\begin{aligned}
& R_{e l 1}=\operatorname{Re}\left(Z_{S C \operatorname{Exp}}\left(f_{c 1}\right)-R_{0}\right) \cdot 3 \\
& C_{d l 1}=\frac{-1}{\operatorname{Im}\left(Z_{\text {SCExp }}\left(f_{c 1}\right)-R_{0}\right) \cdot 2 \pi \cdot f_{c 1}}
\end{aligned}
$$

Fig. 18 presents the impedance behavior of experimental impedance of SC and the first branch. For frequency superior to $\mathrm{f}_{\mathrm{C} 1}$ the branch 1 is sufficient to model correctly the frequency behavior of SC impedance (for HF the experimental spectrum of a SC is a simple pore model as shown in Fig. 8.b). For frequencies inferior to $f_{\mathrm{Cl}}$ branch 1 and SC impedance start to diverge (meaning that several branches are participating to energy storage). Thus the identification of branch 2 parameters will be performed from $\mathrm{f}_{\mathrm{C} 1}$ to lower frequencies.

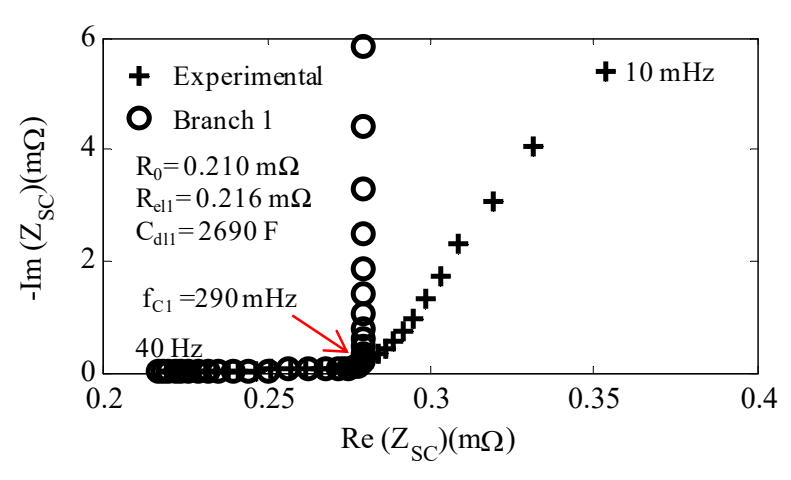

Fig. 18 Comparison to extracted SP model and experimental results

\section{Extraction method for other branches}

When frequencies are inferior to $\mathrm{f}_{\mathrm{C} 1}$ the branch 1 is not sufficient to model SC impedance. That means that two branches in parallel participate to energy storage. Fig. 19 presents the simplification of SC experimental impedance with two parallel branches. Parameters $R_{1}(f)$ and $C_{1}(f)$ are already identified and $R_{2}(f)$ and $C_{2}(f)$ are unknown.

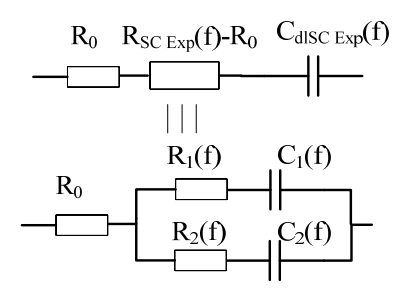

Fig. 19 Simplification of equivalent circuit for extracting branch 2 parameters

With Fig. 19 we can write the following impedance equation : 


$$
\begin{aligned}
& \mathbb{Z}+\left(R_{\text {SCExp }}(f)-R_{0}\right)+\frac{1}{j C_{\text {dISCExp }}(f) \cdot 2 \pi f} \\
& =\not / \alpha+\left(R_{1}(f)+\frac{1}{j C_{1}(f) \cdot 2 \pi f}\right) / /\left(R_{2}(f)+\frac{1}{j C_{2}(f) \cdot 2 \pi f}\right)
\end{aligned}
$$

Equation (25) can be transformed using admittance instead of impedance:

$$
\begin{aligned}
& \frac{1}{\left(R_{\text {SCExp }}(f)-R_{0}\right)+\frac{1}{j C_{\text {dlSCExp }}(f) \cdot 2 \pi f}} \\
& =\frac{1}{R_{1}(f)+\frac{1}{j C_{1}(f) \cdot 2 \pi f}}+\frac{1}{R_{2}(f)+\frac{1}{j C_{2}(f) \cdot 2 \pi f}}
\end{aligned}
$$


Then we can isolate the branch 2 admittance.

$$
\begin{aligned}
& \frac{1}{R_{2}(f)+\frac{1}{j C_{2}(f) \cdot 2 \pi f}} \\
& =\frac{1}{\left(R_{\text {SCExp }}(f)-R_{0}\right)+\frac{1}{j C_{\text {dlISExp }}(f) \cdot 2 \pi f}}-\frac{1}{R_{1}(f)+\frac{1}{j C_{1}(f) \cdot 2 \pi f}}
\end{aligned}
$$

Then we use (28) to simplify (27).

$$
\begin{aligned}
& \frac{1}{R(f)+\frac{1}{j C(f) \cdot 2 \pi f}}= \\
& \frac{R(f) \cdot C(f)^{2} \cdot 2 \pi \cdot f}{1+(C(f) \cdot R(f) \cdot 2 \pi \cdot f)^{2}}+\frac{j \cdot C(f) \cdot 2 \pi \cdot f}{1+(C(f) \cdot R(f) \cdot 2 \pi \cdot f)^{2}}
\end{aligned}
$$

By simplifying (27) with (28) and taking into account only the real part of (28) expression we can define the $\mathrm{k}_{1}$ variable (29).

$$
\begin{aligned}
& \frac{R_{2}(f) \cdot C_{2}(f)^{2}}{1+\left(C_{2}(f) \cdot R_{2}(f) \cdot 2 \pi \cdot f\right)^{2}} \\
& =\frac{\left(R_{S C \text { Exp }}(f)-R_{0}\right) \cdot C_{d l S C E x p}(f)^{2}}{1+\left(C_{d l S C E x p}(f) \cdot\left(R_{S C \text { Exp }}(f)-R_{0}\right) \cdot 2 \pi \cdot f\right)^{2}} \\
& -\frac{R_{1}(f) \cdot C_{1}(f)^{2}}{1+\left(C_{1}(f) \cdot R_{1}(f) \cdot 2 \pi \cdot f\right)^{2}}=k_{1}
\end{aligned}
$$

By simplifying (27) with (28) and taking into account only the imaginary part of (28) expression we can define the $\mathrm{k}_{2}$ variable (29).

$$
\begin{aligned}
& \frac{C_{2}(f)}{1+\left(C_{2}(f) \cdot R_{2}(f) \cdot 2 \pi \cdot f\right)^{2}}=\frac{C_{\text {dlsCExp }}(f)}{1+\left(C_{\text {dISC Exp }}(f) \cdot\left(R_{\text {SCExp }}(f)-R_{0}\right) \cdot 2 \pi \cdot f\right)^{2}} \\
& -\frac{C_{1}(f)}{1+\left(C_{1}(f) \cdot R_{1}(f) \cdot 2 \pi \cdot f\right)^{2}}=k_{2}
\end{aligned}
$$

Then by dividing $\mathrm{k}_{1}$ by $\mathrm{k}_{2}$ we can write (31).

$$
\frac{k_{1}}{k_{2}}=R_{2}(f) \cdot C_{2}(f)
$$

Then we define the cutoff frequency (32) of branch 2 exactly by the same way that for branch $1(20)$.

$$
f=\frac{1}{2 \pi \cdot 3 R_{2}(f) C_{2}(f)} \Leftrightarrow f=f_{C 2}
$$

We solve (32) using the same method described in Fig. 17. The extracted cutoff frequency for the branch 2 of the tested component is $\mathrm{f}_{\mathrm{C} 2}=53.5 \mathrm{mHz}$. This frequency is reported in Fig. 20. Once the cutoff frequency of branch 2 is known we can proceed to $\mathrm{R}_{\mathrm{e} 2}$ and $\mathrm{C}_{\mathrm{d} 22}$. By definition the time constant $\tau_{2}$ of the branch 2 is obtained by multiplying the accessibility resistance $\mathrm{R}_{\mathrm{el} 2}$ by the double layer capacitance $\mathrm{C}_{\mathrm{d} 12}$ of the branch 2 . 


$$
\tau_{2}=\mathrm{R}_{\mathrm{e} l 2} \cdot C_{d l 2}
$$

When the cutoff frequency $f_{\mathrm{Ci}}$ is reached for a SP structure (branch i), we can obtain the values of $\mathrm{R}_{\text {eli }}$ and $\mathrm{C}_{\mathrm{dli}}$.(see (6) and Fig. 8 )

$$
\begin{aligned}
& \mathrm{R}_{e l i}=3 \cdot R_{i}\left(f_{c i}\right) \\
& C_{d l i}\left(f_{c i}\right) \approx C_{d l i}
\end{aligned}
$$

Thanks to (30) we can write for $\mathrm{f}=\mathrm{f}_{\mathrm{C} 2}$ :

$$
k_{2}\left(f c_{2}\right)=\frac{C_{2}\left(f c_{2}\right)}{1+\left(\frac{\tau_{2}}{3} \cdot 2 \pi \cdot f c_{2}\right)^{2}}
$$

Then $\mathrm{C}_{\mathrm{d} 2}$ (37) can be calculated by combining equations (35) and (36). $\mathrm{R}_{\mathrm{el} 2}$ (39) is calculated by combining the expressions of branch 2 time constant $\tau_{2}$ (see equations (33) and (38)).

$$
\begin{gathered}
C_{d l 2} \approx k_{2}\left(f c_{2}\right) \cdot\left[1+\left(\frac{\tau_{2}}{3} \cdot 2 \pi \cdot f c_{2}\right)^{2}\right] \\
\tau_{2}=\frac{1}{2 \pi \cdot f_{c 2}} \\
R_{e l 2}=\frac{\tau_{2}}{C_{d l 2}}
\end{gathered}
$$

As depicted in Fig. 20 the impedance of SC and the 2 branches multipore model start to diverge for frequencies inferior to $\mathrm{f}_{\mathrm{C} 2}$. Thus a third branch must be identified. We can use the same method that we used for identifying branch 2 by adding a $3^{\text {rd }}$ branch in parallel of the two branches structure described in Fig. 19. Nevertheless the cutoff frequency $\mathrm{f}_{\mathrm{C} 3}$ is out of our range of measurements (too low frequency) which doesn't allow us to use the same extraction method. Thus the third branch parameters are identified with an algorithm of fitting based on least square error minimization between experimental impedance of SC and the 3 branches MP model and reported in Fig. 20.

$$
f c_{3}=\frac{1}{2 \pi \cdot \mathrm{R}_{\mathrm{el} 3} \cdot C_{\mathrm{dl3}}}=4.7 \mathrm{mHz}
$$

By observing Fig. 20 we can say that the 3 branches MP model is very accurate to model the impedance behavior of the SC throughout more than 3 decades. The measurement frequency range includes the normal frequency range of SCs usage (for applications going from $0.1 \mathrm{~s}$ to some minutes). 

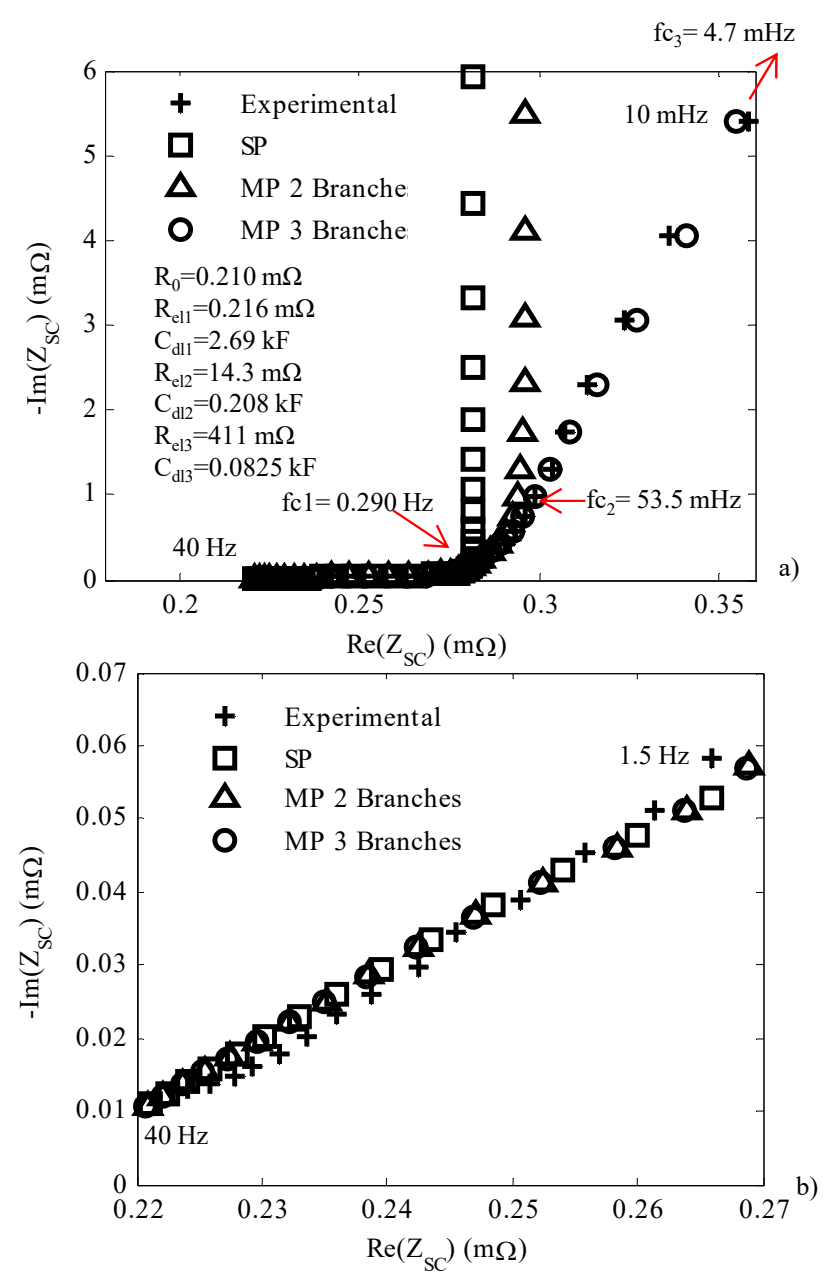

Fig. 20 Fitting of MP model with full frequency bandwidth experimental SC spectrum a) and with HF only b)

Table 1 presents the different time constant of the branches of the tested SC. The different groups of pores appear to own very different accessibilities respecting the hypothesis formulated in (14).

Table 2 Time constants of the different extracted branches

\begin{tabular}{|c|c|c|}
\hline$\tau_{1}(\mathrm{~s})$ & $\tau_{2}(\mathrm{~s})$ & $\tau_{3}(\mathrm{~s})$ \\
\hline 0.58 & 2.97 & 33 \\
\hline
\end{tabular}

\section{POSSIBLE USE OF MP MODEL}

\section{A. Aging monitoring [Erreur ! Source du renvoi introuvable.]}

MP model can be a powerful tool for SC aging monitoring. The advantage of MP model is that it allows following the evolution of different pore groups. The presented results (in Fig. 21 and Fig. 22) are obtained for SCs coming from 2 different manufacturers (A and B) and MP model parameters are extracted with the presented identification method. SC aging is mostly influenced by temperature and voltage. The aging constraints applied on the tested samples are constant $\left(60{ }^{\circ} \mathrm{C}, 2.8 \mathrm{~V}\right)$ and the impedance 
measurement are performed at the aging constraints. To have representative samples three SCs of each manufacturer are aged under the same constraints. The presented aging results are averaged. Aging results for manufacturer A and B are presented in Fig. 21 and in Fig. 22. Parameters evolutions are given in percent. We can notice that during aging the pore accessibility resistance $\left(\mathrm{R}_{\mathrm{eli}}\right)$ to electrolyte is decreasing for every branch. That indicates that during aging the SC pore length is decreasing (the more a pore is short and the more the accessibility resistance of electrolyte in pore $\mathrm{R}_{\mathrm{el}}$ is small [16]). The pore length decrease is accompanied by a decrease of branch 1 capacitance (which represents the main part of SC capacitance (see Fig. 20)) as it tends to reduce the branch 1 storage surface of SC (see Fig. 1 and equation (1)). For branch 2 the capacitance tends to increase possibly indicating that the diameter of the pores of branch 2 are the same order of magnitude that the solvated ion diameter. Thus for entering in branch 2 pores ions are obliged to lose a part of their solvation layer reducing the thickness (d) of double layer which implies a capacitance increase [27] [28] (see equation 1). The evolution of branch 3 (the smallest diameter pores) tends to indicate that they are getting shorter during aging ( $\mathrm{R}_{\mathrm{el} 3}$ decrease) and that they are pore of the same size than bare ion (ion without solvation layer) as the aging tends to $\mathrm{C}_{\mathrm{d} 13}$ decrease (ions are fully desolvated to enter the pores of branch 3 since the beginning of aging). More informations on MP aging monitoring can be found in [6] and [25].
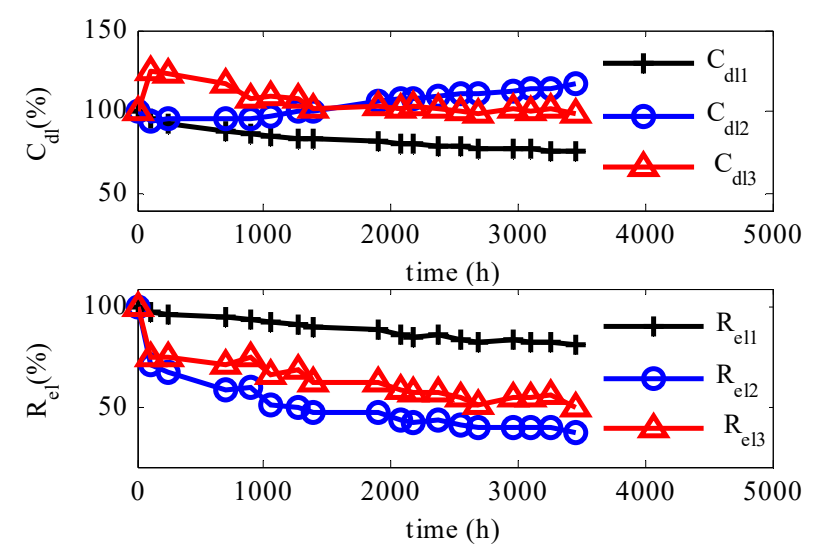

Figure $21 \mathrm{MP}$ model parameters evolution during $60^{\circ} \mathrm{C}, 2.8 \mathrm{~V}$ floating aging (manufacturer A)

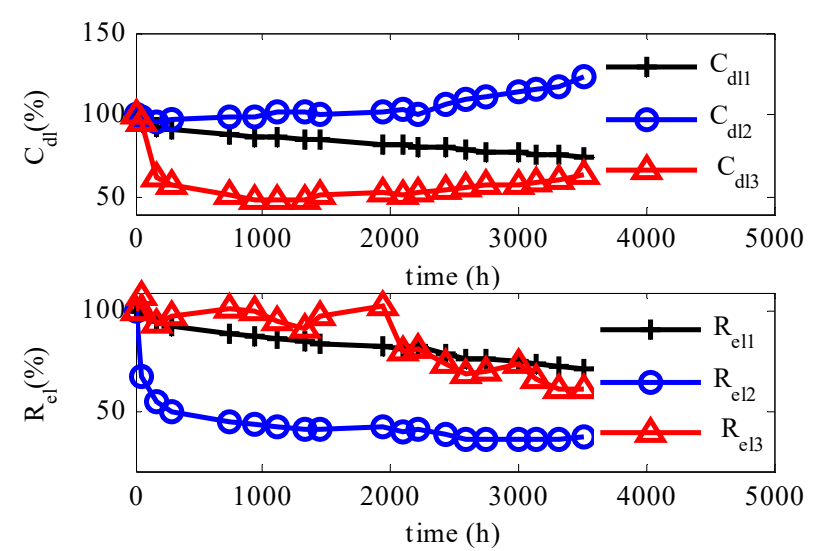

Figure $21 \mathrm{MP}$ model parameters evolution during $60^{\circ} \mathrm{C}, 2.8 \mathrm{~V}$ floating aging (manufacturer $\mathrm{B}$ ) 


\section{B. Time simulation}

A time characterization of one SC has been experimentally realized in laboratory to show the ability of MP model to represent precisely the time behavior of SC. This characterization uses current levels similar to those that are present in hybrid vehicles (braking energy recovering, acceleration....). SC is connected to a high current programmable charge/discharge system. Voltage and current of SC are called $\mathrm{U}_{\mathrm{SC}}$ and $\mathrm{I}_{\mathrm{SC}} \mathrm{SC}$ is charged at $500 \mathrm{Amps}\left(0.17 \mathrm{~A} / \mathrm{F}\right.$ as we are using $3000 \mathrm{~F}$ SC) until $\mathrm{U}_{\mathrm{SC}}$ reaches rated voltage $(2.7 \mathrm{~V})$ and placed in open circuit until time reaches $300 \mathrm{~s}$ (this phase is called redistribution). Experimental results were extracted and fitted with time response by using the inverted Laplace transformation of the MP model impedance. As the test conditions are very different (high current, voltage highly variable) the extracted values are different from a frequency characterization (with fixed voltage and low current level) as shown in Fig. 22. Fig. 22 shows a comparison between time responses of MP model and experimental points. The phenomenon of capacitance non linearity has been taken into account by a linear relationship of capacitance [29] with SC voltage on the main double layer capacitance $\left(\mathrm{C}_{\mathrm{d} 11}\right)$. Fig. 22 a) shows the relevance of MP model to represent SC charge. It can also be noticed that MP represents with high accuracy the phenomenon of charges redistribution between big and small pores (Fig. 22 b)) for a high redistribution time. The advantage of MP model is that it can be easily simulated with simple resistive and capacitive components (contrary to CPE model).

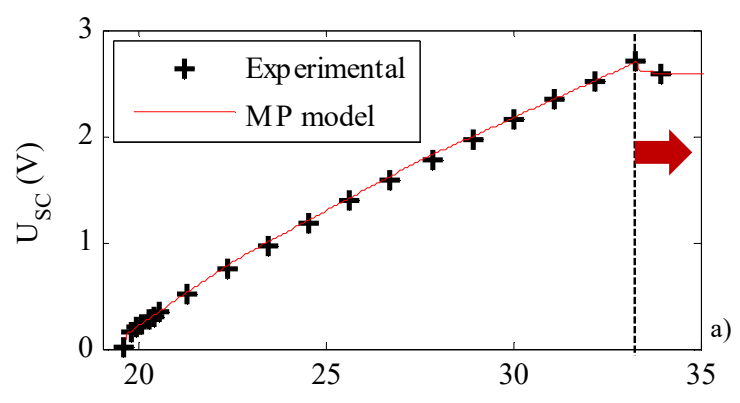

$\mathrm{t}(\mathrm{s})$

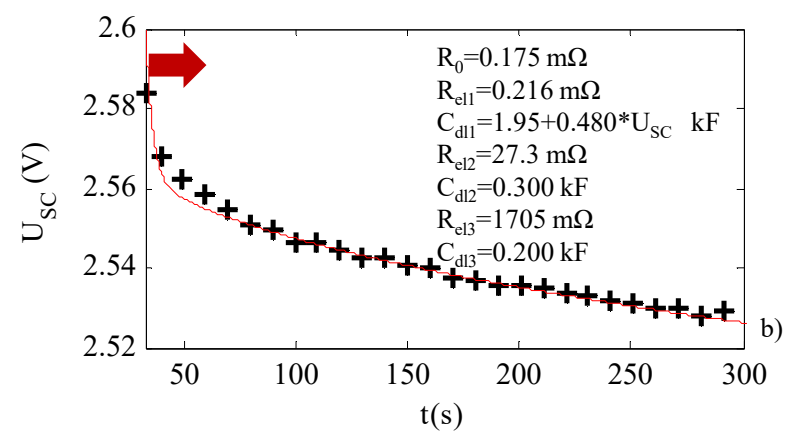

Fig. 22 Time response of SC and MP model during the 500 A charge a) and during the redistribution phase b) 


\section{CONClusion}

This article deals about the identification method for a recent impedance model dedicated to SCs. Due to the presence of ions in the energy storage mechanism (the electrical double layer) and the use of microporous electrodes (to maximize the energy storage surface) the interaction between ions and pores affects a lot SCs impedance behavior. Thus impedance parameters can be used as an analysis tool for SC internal structure. The SCs tested in this article are representative from the most widespread SC technology (i.e. acetonitrile/ activated carbon SCs).

In a first time the paper presents the classic models for SC impedance. Single pore model is the first one to be presented as it is the first one to be published in literature. This model considers all the pores on SC impedance to be exactly the same. It models well SC impedance behavior for HF but fails to model correctly the LF part of SC impedance. This comes from the fact that SC impedance is influenced by the pore size dispersion (which is inevitable on industrial electrodes) for LF. The second conclusion is that only one group of pores (the more accessible to ions) are fast enough to participate to energy storage in HF. Then an alternative model called CPE model is presented. It takes into account the pore size dispersion with a global parameter called dispersion parameter $(\gamma)$. This model is well suited to model both HF and LF frequency behavior of SC impedance. Nevertheless it doesn't deal separately with the different pore groups. This is not really interesting for SCs internal parameters analysis (for example for aging monitoring).

Consequently the multipore model has been developed. It divides the electrode into different single pore structures (called branches) tanks to their accessibility to ions. Under certain hypothesis enounced in this article the accessibility of ions can be related to the pore diameter. The big diameter pores are the most accessible and the smaller one are less accessible. Nevertheless this model is extremely hard to identify with classical fitting algorithms. As a matter of fact the parallel branches imply phenomena such as multiple solutions or local minimums. We consequently developed an identification method base on the successive branch identification with decreasing frequency with no fitting algorithm implied (except for least accessible branch). This paper is the first to propose such a method in the literature. Identification appears to be precise for modeling SC impedance (see Fig. 20), it is linked to the equation and physics of the different single pore structure present on the electrode and it gives always the same parameter set for MP model.

Then the identification method is applied to aging results for 6 SCs coming from two different manufacturers. The evolution of the MP parameters is exploitable and leads to interesting and new conclusions for SC aging confirming the quality of extraction method and the interest of MP model for SC electrochemical parameters analysis. Finally time simulation is proposed as another possible use of MP model. 


\section{ACKNOWLEDGEMENT}

French national research agency (ANR) is supporting these research works which are part of the Supercal project. Supercal is a project held by IMS Bordeaux which combines three academic laboratories (Ampère (Lyon), IMS (Bordeaux), French institute of sciences and technology for transport, development and networks (IFSTTAR)) and manufacturers from transportation and energy storage devices sectors (PSA Peugeot Citroën, Valeo, Batscap).

\section{BIBLIOGRAPHY}

[1] M. Uno and Kukita, A., "Bidirectional PWM Converter Integrating Cell Voltage Equalizer Using Series-Resonant Voltage Multiplier for Series-Connected Energy Storage Cells", IEEE Trans. Power Electron., 2014.

[2] A. Kuperman, M. Mellincovsky, C. Lerman, I. Aharon, N. Reichbach, G. Geula, and R. Nakash, "Supercapacitor Sizing Based on Desired Power and Energy Performance”, IEEE Trans. Power Electron., vol. 29, no. 10, pp. 5399-5405, Oct. 2014.

[3] J. C. Schroeder and F. W. Fuchs, "General Analysis and Design Guideline for a Battery Buffer System With DC/DC Converter and EDLC for Electric Vehicles and its Influence on Efficiency”, IEEE Trans. Power Electron., vol. 30, no. 2, pp. 922-932, Feb. 2015.

[4] M. Averbukh, S. Lineykin, and A. Kuperman, "Portable Ultracapacitor-Based Circuit for Emergency Staring of Internal Combustion Engines", IEEE Trans. Power Electron., 2014.

[5] B. Hredzak, V. G. Agelidis, and G. D. Demetriades, “A Low Complexity Control System for a Hybrid DC Power Source Based on Ultracapacitor-Lead Acid Battery Configuration”, IEEE Trans. Power Electron., vol. 29, no. 6, pp. 2882-2891, Jun. 2014.

[6] R. German, P. Venet, A. Sari, O. Briat, and J.-M. Vinassa, "Improved Supercapacitor Floating Ageing Interpretation Through Multipore Impedance Model Parameters Evolution”, IEEE Trans. Power Electron., vol. 29, no. 7, pp. 3669-3678, Jul. 2014.

[7] D. B. Murray and J. G. Hayes, "Cycle Testing of Supercapacitors for Long-Life Robust Applications", IEEE Trans. Power Electron., vol. 30, no. 5, pp. 2505-2516, May 2015.

[8] O. Laldin, M. Moshirvaziri, and O. Trescases, "Predictive Algorithm for Optimizing Power Flow in Hybrid Ultracapacitor/Battery Storage Systems for Light Electric Vehicles”, Power Electron. IEEE Trans. On, vol. 28, no. 8, pp. 3882-3895, 2013.

[9] A. Lahyani, P. Venet, A. Guermazi, and A. Troudi, "Battery/Supercapacitors Combination in Uninterruptible Power Supply (UPS)", Power Electron. IEEE Trans. On, vol. 28, no. 4, pp. 1509-1522, 2013.

[10] B. Hredzak, V. G. Agelidis, and Minsoo Jang, "A Model Predictive Control System for a Hybrid Battery-Ultracapacitor Power Source”, IEEE Trans. Power Electron., vol. 29, no. 3, pp. 1469-1479, Mar. 2014.

[11] D. B. Wickramasinghe Abeywardana, B. Hredzak, and V. G. Agelidis, "Single-Phase Grid-Connected LiFePO4 Battery-Supercapacitor Hybrid Energy Storage System with Interleaved Boost Inverter", IEEE Trans. Power Electron., pp. 1-1, 2014.

[12] W. Wang, M. Cheng, Y. Wang, B. Zhang, Y. Zhu, S. Ding, and W. Chen, “A Novel Energy Management Strategy of Onboard Supercapacitor for Subway Applications With Permanent-Magnet Traction System”, IEEE Trans. Veh. Technol., vol. 63, no. 6, pp. 2578-2588, Jul. 2014.

[13] F. Ciccarelli, A. Del Pizzo, and D. Iannuzzi, "Improvement of Energy Efficiency in Light Railway Vehicles Based on Power Management Control of Wayside Lithium-Ion Capacitor Storage”, Power Electron. IEEE Trans. Vol. Issue 1, vol. 29, no. 1, pp. 275 - $286,2014$.

[14] S. Moayedi, F. Cingoz, and A. Davoudi, "Accelerated Simulation of High-Fidelity Models of Supercapacitors Using Waveform Relaxation Techniques", Power Electron. IEEE Trans. On, vol. 28, no. 11, pp. 4903-4909, 2013. 
[15] A. Eddahech, O. Briat, N. Bertrand, Jean-Yves Deletage, and J.-M. Vinassa, "Behavior and state-of-health monitoring of Li-ion batteries using impedance spectroscopy and recurrent neural networks”, Int. J. Electr. Power Amp Energy Syst., vol. 42, no. 1, pp. 487 - 494, 2012.

[16] R. D. Levie, "Electrochemical response of porous and rough electrodes, Advances in electrochemistry and Electrochemical Engineering", Wiley Intersci., vol. 6, pp. 329-397, 1967.

[17] M. technologies, Product Guide, Maxwell Technologies, K2 series Ultracapacitors. 2009.

[18] M. Makdessi, A. Sari, P. Venet, P. Bevilacqua, and C. Joubert, “Accelerated Ageing of Metallized Film Capacitors under High Ripple Currents Combined with a DC Voltage", IEEE Trans. Power Electron., pp. 1-1, 2014.

[19] R. Lin, P. Taberna, J. Chmiola, D. Guay, Y. Gogotsi, and P. Simon, "Microelectrode Study of Pore Size, Ion Size, and Solvent Effects on the Charge/Discharge Behavior of Microporous Carbons for Electrical Double-Layer Capacitors”, J Electrochem Soc, vol. 156, pp. 7-12, 2009.

[20] C. A. Toles, W. E. Marshall, and M. M. Johns, "Surface functional groups on acid-activated nutshell carbons", Carbon, vol. 37 , no. 8, pp. 1207 - 1214, 1999.

[21] J. Gamby, P. L. Taberna, P. Simon, J. F. Fauvarque, and M. Chesneau, "Studies and characterisations of various activated carbons used for carbon/carbon supercapacitors", J. Power Sources, vol. 101, no. 1, pp. 109 - 116, 2001.

[22] L. Long and P. H. Bauer, "Practical Capacity Fading Model for Li-Ion Battery Cells in Electric Vehicles", Power Electron. IEEE Trans. On, vol. 28, no. 2, pp. 5910-5918, Dec. 2013.

[23] H.-K. Song, H.-Y. Hwang, K.-H. Lee, and L. H. Dao, "The effect of pore size distribution on the frequency dispersion of porous electrodes", Electrochimica Acta, vol. 45, no. 14, pp. $2241-2257,2000$.

[24] R. Kotz and M. Carlen, "Principles and applications of electrochemical capacitors", Electrochimica Acta, vol. 45, no. 15-16, pp. 2483 - 2498, 2000.

[25] A. Hammar, P. Venet, R. Lallemand, G. Coquery, and G. Rojat, "Study of Accelerated Aging of Supercapacitors for Transport Applications", Ind. Electron. IEEE Trans. On, vol. 57, no. 12, pp. $3972-3979$, Dec. 2010.

[26] C.-J. Chien, S. S. Deora, P. Chang, D. Li, and J. G. Lu, "Flexible Symmetric Supercapacitors Based on TiO2 and Carbon Nanotubes", IEEE Trans. Nanotechnol., vol. 10, no. 4, pp. 706-709, Jul. 2011.

[27] J. Chmiola, G. Yushin, Y. Gogotsi, C. Portet, P. Simon, and P. L. Taberna, "Anomalous Increase in Carbon Capacitance at Pore Sizes Less Than 1 Nanometer", Science, vol. 313, no. 5794, pp. 1760-1763, 2006.

[28] P. Simon and Y. Gogotsi, “Charge storage mechanism in nanoporous carbons and its consequence for electrical double layer capacitors," Phil Trans R Soc, vol. 368, no.1923, pp. 3457-3467, 2010.

[29] L. Zubieta and R. Bonert, "Characterization of Double-Layer Capacitors for Power Electronics Applications,” IEEE Trans. Ind. Appl., vol. 36, no. 01, pp. 199-205, Feb. 2000. 